Johannes Wilhelm*

\title{
What We Want to Tell You Now (Provisionary): A Play by High School Students from Fukushima Prefecture
}

https://doi.org/10.1515/asia-2019-0005

\section{Introductory Comments}

This play was written by students of a high school located only $45 \mathrm{~km}$ north of the damaged Fukushima Daiichi nuclear power plant in the coastal area of the prefecture. The play reflects the feelings of young people from Fukushima and has been performed nationwide in many places since its premiere in Tokyo on the first anniversary of the Great Tōhoku Earthquake. The word "provisional” in brackets at the end of the title refers to the fact that the nuclear disaster in Fukushima is currently progressing and is by no means over.

The play has received notable attention nationwide and was highly praised by critics, especially as it was written by young women from Fukushima who themselves were directly affected by the events and critically examined their situation and feelings after the catastrophe with all its complex facets.

Over time, however, the authors of the work were exposed to increasing and sometimes even personal attacks. These "critics" expressed their dissatisfaction with the play, for example, because in their opinion, the reconstruction would finally take on visible forms and a critical discussion would only cause turbulence and anger. In addition to this criticism, which can be described as more paternalistic, there were also criticisms that increasingly took on the quality of shit-storms on the internet. The criticism of the play was in some cases that much displeasing that some of the original participants even turned away from it in order to avoid future damage. That is why the teacher in charge asked to hide the names of the authors within this translation.

In December 2017, Akemi Yamauchi consulted Johannes Wilhelm on these circumstances, so that after thorough examination they concluded that the play had enough content for further discussion and that the theme of the play was by

Translated by the "Imakari translation project" under the supervision of Johannes Wilhelm and Akemi Yamauchi, with Yoshihiro Watanobe, Akasaka Norio, and Tomoko Niwa

*Corresponding author: Johannes Wilhelm, Keio University, Shonan Fujisawa Campus, 5322 Endo Fujisawa, Kanagawa 252-0882, Japan. E-mail: hiraganaboy@gmail.com 
no means limited to the region around Fukushima or Japan alone. In their view, the type of criticism mentioned was unfounded and malicious, especially since the work expressed the subjective view of young people, which does not necessarily have to correspond to the view of adults. In addition, the play also wants to be a contribution by critical young people who do not have the right to vote and are thus overlooked in the political implementation of the reconstruction, but also in the desired form of a future Fukushima. At the same time, the two were concerned that the debate surrounding the play, but also that about the consequences of the catastrophe, was dying down, although the present situation in the affected regions is still in the midst of reconstruction, which is taking on some absurd forms, such as in the case of decontamination work or the construction of tsunami protection walls along the coast. In order to give the discourse a new twist, the idea of the translation project was born, primarily into English, the lingua franca of our time. It is possible that an interested audience will be given a view that is otherwise denied for reasons of language, so that translations and performances in other languages may become possible based on the English translation, and the discourse around Fukushima and the play will be freed from the apparently unavoidable constraints found in Japan. The translation of the play is the result of a project in February 2018 with the original authors, who translated the play into English together with students of the same age who grew up in several languages at Keiō University (Toshino Carter, Ayana Futagawa, Daita Satō). The project was initiated and led by Johannes Wilhelm and Akemi Yamauchi, with Akasaka Norio, Tomoko Niwa and Yoshihiro Watanobe acting as commentators and editors. The text of the translation was based on the version printed in the Japanese magazine Kagaku, ${ }^{1}$ which was enhanced with additions from various performances of the group as much as personal communication during the translation project.

In translating the original text, much care was taken to ensure, among other things, that it belonged to young people who had their own forms of expression. For this reason, the American language and its slang was preferred to British English that is common in the academic world. However, there were also important aspects that only reveal themselves in Japanese, such as the names of the protagonists. For instance, Sakura, a quite common maiden name, literally means cherry or, in the case of Japan, stands for cherry blossoms in spring, the time of year when the catastrophe occurred. The cherry blossom serves as a symbol of the beauty of life, but at the same time the short flowering phase also stands for the fact that any life will one day unavoidably perish.

1 Kagaku 82.10 (2012): 1166-1172.

As a native speaker, Andrew Mitchell did the final proof of the translation. 
Since the Japanese school system of the school year ends in March and begins in April, it also serves as a symbol of farewell in the school context, which is often sung about in folk and pop songs. Another name, Nozomi, literally means hope, so that her death towards the end of the play gives the work a very special touch. The team of translators also came up with the idea of anglicizing the name into "Hope", but this was discarded in the process for reasons of consistency.

Some passages in the text require a certain amount of cultural or background knowledge, which is why the necessary information is provided in footnotes. Stage instructions are provided in italics.

The participants of the translation project hope that the play will also inspire people all over the world to try a translation into their specific language. For this reason, the following e-mail contact is provided: hiraganaboy@gmail.com

\section{Scene 1}

FULL LIGHTS (orange background, it's in the afternoon)

Inside classroom

Nozomi/Sakura: Ready, set, go! Magical Banana, if you say Banana, I think ... ? ${ }^{2}$

Maki: ... Fruits.

Sakura: If you say fruits, I say Tropical!

Nozomi: If you say tropical, I say Island.

Maki: If you say Island, I'll say Ocean.

Sakura: If you say Ocean, I say Tsunami.

Nozomi: If you say Tsunami, I say Earthquake.

Maki: If you say Earthquake, I say ... no STOP, STOOOOOP!

Nozomi: Hey! We were just getting started.

Maki: That's not the problem, the problem is that it is going in a negative direction!

Nozomi: It doesn’t matter. So what?

Maki: No, that's not good. Come to think of it, who does Magical Banana as high school students?

Sakura: Now, now. Maki, Nozomi. You guys tried.

2 Magical Banana is an associative game popular among children. 
Nozomi: Sakuraaa, you're not listening well.

Maki: Sakura, you don't have to go with her flow.

Sakura: Go with the flow?

Maki: NO!

Nozomi: Shoot, I thought I finally found a good way to pass the time.

Maki: Oh, that's a big NO-NO.

Nozomi: But I will not give up!

Sakura: Really?!

Maki: My goodness, please give up!

Nozomi: Why do I have to give up? Nope, I won't!

Maki: ... Fine. I will break you. By breaking your head.

Sakura: Makiii, Stop! Someone's going to die.

Nozomi: Yeah! Don't commit another crime.

Maki: Huh? I don’t remember committing a crime.

Nozomi: Right about now.

Sakura: Anyways, Nozomi, you should apologize for now.

Nozomi: What? No. Nooooo.

Maki: Huh? Are you in any position to say that?

Maki grinding her fist in Nozomi's head

Nozomi: I'm sorrryyyyy.

Sakura: Oh, it wasn't so hard to persuade you after all.

Maki: Well, I'll let it go. More importantly, you guys. Don’t use those banned words.

Nozomi: Whaaaaaat?! WHY?

Maki: Shut up! It makes me feel uncomfortable!

Nozomi: Huh? But ... everyone's using it.

Maki: No. Others are others. We have our own rules. From now on, NO ONE uses that word. Understood?

Sakura: M ... mmother.

Nozomi: But, mom. If we're banned from this, do you have anything else that's fun?

Maki: Let’s do our favorite homework. 
Nozomi: Mom, I reject. Since we have the classroom for ourselves, we have to use it more wisely!

Maki: Then Nozomi, what do you want to do?

Nozomi: Ummm ...

Maki: Objection.

Nozomi: At least hear me out!

Sakura: Now now. Let's just keep talking. After all, we don’t belong to any club.

Nozomi: This sucks. We have nothing to talk about.

Maki: You're annoying.

Sakura: Hmmm ... Oh! I do have something to talk about.

Nozomi: What is it?!

Maki: That's a fast comeback.

Sakura: I found a lot of cup noodles on the shelf.

Maki: Then, what happened?

Sakura: But I looked at them and the expiration date is almost due.

Maki: ... so?

Sakura: Can someone have it?

Nozomi: Why didn't you tell me earlier? What is this, a relief supply?

Maki: You, shut up. How many do you have?

Sakura: Fifty.

Nozomi: That's so many!

Sakura: You know. We stocked them when the earthquake happened.

Maki: Oh yeah. We did the same.

Sakura: I accidentally bought cup noodles even though we had a water outage.

Nozomi: Sakura, don't sweat it/Cheer up.

Maki: You piss me off!

Maki hits Nozomi

Nozomi: Ouch!

In the background Maki and Nozomi are quarreling. Sakura begins talking.

Sakura: Come to think about it, it has been a year.

Maki: ... Since the earthquake? 
Nozomi: Surprisingly, it has passed quickly.

Sakura: Really? It went by really slow for me.

Maki: By the way, is it true that a panda is coming to Miyagi? ${ }^{3}$

Sakura: Seems so.

Nozomi: Wanna go?

Maki: If I'm bored.

Nozomi: How about you, Sakura?

Sakura: If you two are going, maybe I'll go.

Maki: You know what I think. I guess I shouldn’t say, but do we need Pandas?

Sakura: I guess it's okay. It's for the restoration anyways.

Maki: But, we say restoration, but no one will come all the way here since we have the nuclear power plant.

Nozomi: Well, the people in Tokyo can go to Ueno. ${ }^{4}$

Maki: Right, they’ve been talking ‘bout economic effects, but I wouldn't go to see it.

Sakura: You have a point.

Nozomi: By the way, on an unrelated topic, when does the train connection resume between Sōma and Sendai? ${ }^{5}$

Maki: It really has nothing to do with what we were talking about.

Sakura: Isn’t it still a long way off? Maybe a few years?

Nozomi: What! What did you say? Then, we can't go to see the Pandas.

Sakura: You're still hung up on that, eh? I see you're still hung up on Pandas.

3 It was announced on May, 2011 that the Yagiyama Zoo in Sendai (Miyagi Prefecture) will be awarded a panda for the first time to cheer up children in the disaster area. The popular television agency "Johnny's net" has raised money for the project since then, but until the end of 2018, the year of the 40th anniversary of the resumption of diplomatic relations between Japan and the People's Republic of China, no loan agreement was signed between the states, probably due to the difficult bilateral relations under Prime Minister Abe's government.

4 Ueno is located in the northern part of the centre of Tokyo. The local zoo is the best-known in the country. By the way, Ueno and its railway station also stand as a symbol of an entrance gate for the many migrant workers from the Tōhoku region to the city and the parks and amusement areas near the railway station were popular meeting places for these migrant workers.

5 Both, Sōma and Sendai are cities within $100 \mathrm{~km}$ north of the wrecked nuclear power plant. While Sendai is a metropolitan area with more than a million inhabitants, Sōma is a much smaller municipality in the coastal area of neighbouring Fukushima Prefecture in the south. 
Maki: But the rail replacement bus service is coming part of the way, so you can get to Sendai.

Nozomi: What! I can't believe this!

Sakura: You didn’t know?

Nozomi: Well, I was a couch potato after the big quake ... so?

Sakura: Don’t lie.

Nozomi: Oops.

Maki: Somehow I'm annoyed.

Maki hits Nozomi again.

Nozomi: ... Ow!

Sakura: ... Still, like after the earthquake, we have been lonely and a lot of things have happened.

Maki: That's because the roads and trains haven't been restored yet.

Sakura: Exactly, it's hard to ride my bike on the sidewalk. I wonder if they could fix the roads a bit faster.

Maki: I know right.

Nozomi: I mean, I've always thought of saying this, but people say, restoration, restoration, but like Sōma hasn't changed one bit. I should say maybe it's because of the nuclear power plant? Is it because of the harmful rumors? It's either the government not providing financial aid. Or is it that we have been forgotten ...

Maki: Nozomi’s being serious ... ! Maybe spears will fall from the sky tomorrow.

Nozomi: Makiii! I wonder what kind of image you have of me/I wonder how you think of me.

Maki: Like this.

Nozomi: I think about these things too you know ... at a certain level ...

Maki: ... Hmmm.

Sakura: But I agree with Nozomi. Fukushima lost its population again so.

Maki: Well, it's always the same, and honestly, I don't think people want to go to Fukushima now. Especially, since the nuclear power plant is near the beach side.

Sakura: But, the amount of radiation has decreased so it's okay ... ?

Maki: But, what if? What if there's a problem with the nuclear plant again? We would have to evacuate next time for sure.

Sakura: Evacuation ... I remember everyone evacuating when the earthquake occurred ... do you think the rumors about radioactive contamination will ever go away?

Maki: Well, I guess all of this is all because of the nuclear power plant? 
Nozomi: Ughhhh! WHY! Why did this happen?! Fukushima used to be such a great place. All because of the earthquake ... ! Seriously, I can’t take it anymore. I want to cry.

Sakura: Hey, Maki. As I thought, there's a hurricane landing.

Maki: No. It's the day that the Mayan Prophecies become real.

Nozomi: Hey, the two of you. Seriously, enough of your jokes/stop messing around/that's enough. I'm going to get mad. Once I flip out, I'm scaryyyy. I'm going to whelm/sink you guys into the Matsukawaura ... woooo! ${ }^{6}$

Maki: You want us to soak ourselves into the radiated ocean? I will sink right back at you.

Nozomi: My goodness, Maki that's so scary/terrifying/freaks me out.

Sakura: I want to join in/Let me in!

Maki: No, you don't have to/need to.

From here, make some noises. (Improvisation)

The school chimes rings to suggesting to go home, and the announcement is played.

Sakura: Wow, look at the time/time flies.

Nozomi: Whaaaaat! It's already six?!

Maki: Actually, it's better. Let's call it a day/Time to go home.

Nozomi: Noooooo/No way! Let's stay/Come on!

Maki: Didn’t you hear? The school chime!

Maki pinches Nozomi's cheek.

Nozomi: Ahh ... outch! Ow!

Sakura: True, if school gets closed, it won’t be funny.

Maki: Exactly ... so, I'm heading home. Byyyyye.

Nozomi: Eh!/ What?! That’s impossible! What's up with those 'Going-Home-skills'.

Maki: ‘Going-Home-skills’ rather, ‘Running-away skills’ no? ... Maki has ran away/escaped/ runaway Maki.

Maki walks out/exits towards the right-hand side of the stage.

Nozomi: Hey! Wait up!

Sakura: Wait for me, Maki! Nozomiii, hurry!

Nozomi struggles to organize her bag.

6 Matsukawaura is a lagoon near the city of Sōma. 
Nozomi: Hey! Wait up! ... Heck! It's going to take me a while packing all my stuff, so I'll leave a little later. Sakura, go ahead without me!

Sakura: Really? Are you sure you're okay (alone)?

Nozomi: Yeah. Don't mind me.

Sakura: Okay, I’ll see you tomorrow!

Nozomi: Bye! See ya!

Sakura exits to the right-hand side of the stage. Nozomi stands alone. Light points to the middle.

Nozomi: Ahem! AHHHHH! All because of Fukushima. Radiation. I can't help but hate it. I can't take it anymore ... even being here.

STAGE BLACKS OUT

\section{Scene 2}

\section{FULL LIGHTS}

Background blue. Imagined rain

Sakura faces down at the desk. Maki runs into Sakura with upset from left side.

Maki: Sakura!

Sakura: Maki!

Maki: Why didn’t you pick up the phone! I was so worried about you!!

Sakura: ... I'm sorry.

Maki: ... Is that true? Did Nozomi really kill herself ... ?

Sakura nods.

Maki staggers and sits down on the chair.

Maki: She ... did commit suicide.

Sakura: ... Yea.

Silence. Heavy atmosphere.

Maki: Seriously, why did she suddenly commit suicide ... ? She was doing well till very recently ...

Sakura: Only she know the truth.

Maki: ... Yea. We'll never know.

Sakura: You didn’t hear anything from Nozomi? 
Maki: No ...

Sakura: Okay.

Maki: But why ... ? Is that because I was always tough on her?

Sakura: No! Of course not ... not for such a reason ... She wouldn’t commit suicide ...

Maki: ... Sakura ...

Sakura: It's not your fault.

Maki: I guess so ... Did you know much about her?

Sakura: ... why?

Maki: I mean, you were close to her and I thought you may know ...

Sakura: ... um, Maki. Do you remember she came from another school?

Maki: Yea.

Sakura: She used to live in the restricted area, and all of her family were swept away ...

Maki: What!

Sakura: ... That's the reason why she came here.

Maki: She never told me!

Sakura: It's just ... No-one really talks about it. There are so many people who have no choice but live here because they lost their families from the tsunami and power plant disaster.

Maki: I know! But ... I didn’t know about Nozomi. Didn’t know her situation was that bad.

Sakura: I didn't know either at first ... You know, I was asking her about her family like everyone does and she told me ... I shouldn't have done ... I'm so stupid ...

Maki: It can't be helped.

Sakura: Is it ... ? I hope so. There were issues at home ...

Maki: Home? ... wait, she didn’t have any family, right? Then how could she manage?

Sakura: She was living with her relatives, but they were cattle farmers ...

Maki: What! They are suffering from radiation right now, aren't they!?

Sakura: Yea ... I saw on TV that people don't buy milk because they are worried about the radiation, and tons were wasted.

Maki: Must be tough ... Maybe her relatives were stressed?

Sakura: Yea ... They came down hard on her because of that. She laughed it off.

Maki: Abandoned from her family and relatives ... If I were her, I would wanna commit suicide too ... She didn't have anyone to trust or lean on to. Not a single person. I just can't believe she could act so normal at school. 
Sakura: Probably she knew she couldn't act depressed because if she did, many people would have worried about her ... So that's why she tried to pretend that she was okay.

Maki: ... Sakura, it sounds like you really knew Nozomi.

Sakura: ... Actually my house got swept away too..

Maki: ... No.

Sakura: Oh! But only the first floor was washed away, the second floor was okay. My home was torn down later.

Maki: I'm sorry!

Sakura: Why? It's okay. I didn't tell you.

Maki: But ... I'm so sorry.

Sakura: Yea.

Maki: Perhaps Nozomi was like that too ... She wanted to talk about it but couldn't ... I should have gotten my shit together.

Sakura: It's not your fault.

Maki: ... I still don’t get it. Why did Nozomi kill herself? What made her decide?

Sakura: ...

Maki: Hey. is there anything else you haven't told me?

Sakura: To be honest, she told me not to tell anybody ... but ...

Sakura takes out phone from her pocket.

Sakura: Nozomi discovered these shit-storms on the internet ...

Sakura accesses the web/internet and gives her phone to Nozomi.

Maki: What the ... hell ...

\section{LIGHTS DIM DOWN}

Post1: "Fukushima-citizens having power plant was contaminated by radiation LOLLL."

Post2: "DON’T ACT LIKE VICTIMS, FUKUSHIMA.”

Post3: “Lock them up inside radiation! Stay away! Don’t infect other NORMAL people with radiation!"

\section{ALL LIGHTS UP}

Maki: Awful ...

Sakura: Nozomi told me not to tell when she showed me, she said it's hard but I am okay ... Maki: Did this trigger ... ?

Sakura: No, it's not. But this might have been a trigger ... 
Maki: Okay ..., oh ... now I remember!

Sakura: Huh?

Maki: Nozomi said before, she thinks she won't be able to marry anyone.

Sakura: Huh? Why?

Maki: Because of the effect of power plant. We are damaged by rumours and there is discrimination against anything Fukushima. What if people asked you about radiation when you get married and have kids?

Sakura: No, you're thinking too much..

Maki: Some people think in this extreme way!

Maki shows the phone to Sakura and says

Maki: If we bear a disabled child, they'll blame us.

Sakura: But it’s not our fault!!

Maki: I KNOW!

Sakura: ( ... silence ... )

Maki: If there were no plants, we wouldn't have to feel this way. We are left behind and treated like outsiders with no improvement in our lives.

Sakura: But, because of the plants, we were well-off.

Maki: That's right. Our region had benefited from the investments in return for the risk. But our generation didn't decide that, huh?

Sakura: Yea, but they all act in their everyday lives as if nothing has happened. Quite honestly: I am scared.

Maki: So do I. But they all gave up. It is clear that we cannot defeat the invisible fear. The sense of risk has vanished.

Sakura: It happened, we have no choice. Nozomi said the same thing.

Maki: We have no trouble if we can forget about this.

Sakura: Yeah ...

Maki: Sakura.

Sakura: What?

Maki: Sakura, you've talked about it, so I think I'm gonna start talking, too. ... You know, I lost many friends in the disaster ...

Sakura: (silence)

Maki: Like the others, they were carried away by the tsunami. But when you hear the stories, it doesn't appear to be real ... 
Sakura: ...

Maki: Honestly, I was relatively untouched by major damage compared to others ... At first, I was happy that all my family were safe after disaster ... safe ... hmm ... safe.

Maki: But since my close friend was gone, all vanished, and additionally things are moving on. Same as with the power plants. Nozomi ... I must admit it might be rude to her, but, even this time it's a classic pattern. Some high-ranking people say that everything is under control, but it is not yet for us ...

Sakura: Maki.

Maki: True, right? At first, other people are all bystanders, but only few people really know ... they don't know what I know.. They don't know what we know. Isn't it. They don't even listen to us. No matter how loud we're screaming, the outreach is limited.

Sakura: But we can spread our opinion by using the Internet. We can use it, right?

Maki: That's right. But if they attack us again, like they did with Nozomi?

Sakura: Well ...

Silence for a moment. Maki, turns to front and starts screaming.

Maki: Someone! Please listen!

Sakura: What!? Maki!?

Maki: Please! Please someone listen to what I tell you! Don't ignore a child's appeal! Don't forget about this present situation! Don't forget that there are people who are suffering to death just like Nozomi!

Maki: Please! Please! Look into my eyes and give me an answer!

Maki, is out of breath.

Maki: Sakura, I told you so. Even though I scream, nobody will ever notice me! Nobody listens. Even if they listen to me, eventually they forget.

Sakura: Maki ...

Maki: I think her suicide will also soon vanish from everybody's memory. Maybe, it will appear on the news, but they will all forget it at the end of the day.

Sakura: Maki ... that's wrong.

Maki: What? What's wrong?

Sakura: Even if you scream, nobody will notice. Everybody will forget. But, not all people are like that. It is possible that there is someone who can take this seriously the way we do. So, we have to tell it. We can't lose against despair.

Maki: To tell others about it and keep living? ... Nozomi is already dead ... I can’t ...

Sakura: Come on! Pull yourself together! Everyone’s the same.

Maki: Stop embellishing things! 
Sakura: Honesty, I panicked when my home got washed away by the Tsunami. But, when the Self Defense Forces came to rescue us, they also cheered me up. Then, I realized, nothing comes from worrying. So, I have to do my best.

Maki: ... ...

Sakura: Nozomi isn't here anymore, but we have to make full use of our lives, even for Nozomi. I think, this is the only thing we can do for her. So, I don't find the right words, but, we have to overcome this together!

Maki: Overcome together ... Sakura, I wish I was like you, saying things like that.

Sakura: Huh? Why? How come?

Maki: I can’t have any hope. My hope is broken. Nozomi died, and I can't hardly see anything. What can I believe in now?

Sakura: Maki ...

Maki: We've been robbed! Our freedom. Well, but, what is that supposed to be, freedom? No more safe food. No more safe soil. No more safe water, nor ocean. Is it freedom to live under the constant terror of radiation? The power plant is so close to us, but this is outside the official danger zone, so not even compensation is paid. I want a secure future! Oh! My my head went coocoo!

Sakura: Ma ..., Maki!

Maki: “It is allright!”, “We're all fine!”, is this freedom? I don’t get it. Being stigmatized. Nozomi died because of this! Nobody listens to our opinion! It’s impossible to live with hope!

Sakura: No, wait Maki!

Maki, runs around. Sakura chases after.

Both of them then run off the stage.

\section{BLACKOUT}

ONE LIGHT UP (in the middle of the stage)

(background with blueish or purple light)

Nozomi stands up and starts counting the (imaginary) persons above her.

Nozomi “455, 456,457, 458 ... So many people died in Soma during the disaster. Can I become Number 459 ?

Nozomi looks around and goes to the center of the stage.

Nozomi (final monologue): Why don't they understand? You know it! Did I say something wrong? Fukushima is in trouble. Polluted by radiation, other people are looking at us with cold eyes. Am I wrong? Why do I have to suffer this way? Why are you judging me? I just wanna be heard. That's all I'm asking for. Are you listening seriously to what I'm saying? You don't say anything! 
Stop messing around with me! Don't pretend to know anything! Do you know anything about me? You just care about the adults' opinions, but, you won't listen to what children have to say. Yet, you're talking about the future of the children. Future ... what do you know of the future ...

Hey, you were the guys who destroyed everything!

Reputation? Public opinion? Media? Those who are stigmatizing and criticizing us on any occasion, you guys are thinking I'm just a naïve brat, right? Right?

Of course, you do! Because it's not your business. Nobody knows about others' feelings. Nozomi is still missing. Forever. Forever ... Because, this is the reality. Please. Please, help us! Nozomi, sits down.

BLACKOUT

END OF THE PLAY 